\title{
Metaphor, Metonymy and Cognitive Construal of Polysemy
}

\author{
Sun Bianqi \\ Department of Foreign Language, Beijing Institute of Graphic Communication
}

\begin{abstract}
Polysemy is a common phenomenon of language and polysemous words are considered to be semantically related. This paper aims at exploring the cognitive mechanism of metaphor and metonymy in sense extension and discussing the application of metaphoric and metonymic conceptualization in English vocabulary teaching.
\end{abstract}

Index Terms - metaphor, metonymy, cognitive, polysemy, vocabulary

\section{Introduction}

Vocabulary is the basic unit of language. People can never overestimate the importance of vocabulary acquisition in language learning. According to the syllabus, non-Englishmajor college students are required to master around 5000 English words, which pose a serious challenge for most college students. Although students spend most of their time expanding their vocabulary, yet the result is not satisfactory. According to the survey conducted in the class, most students complain that the biggest difficulty has been the polysemy, each of which has numerous meanings. It is known that most English words, in a sense, are polysemous words. Éva Kovács (2011) thinks polysemy, the phenomenon whereby a linguistic unit exhibits multiple distinct yet related meanings, is a very common feature of all languages. In fact, almost every word in any language is polysemous to some extent. Consider such words in English as get, hand and hot, etc. Polysemy is justly considered to be a necessary means of language economy[1].

In traditional English teaching class, teachers usually put relatively more emphasis on Chinese equivalent explanation, ignoring the huge differences between the two languages and cultures. Very little attention is given to the cognitive way of in-depth vocabulary acquisition, let alone the relatedness of the senses of lexical items. This directly results in the phenomenon that relatively large vocabulary does not help much in genuine expression. The problem lies in the failure of effective teaching of polysemous words interpretation.

In recent years, with the development of cognitive linguistics, scholars begin to give attention to the study of polysemy. They start to study this linguistic phenomenon from a cognitive point of view, exploring the causes and development path of its occurrence. As Ullmann (1959) puts it,

"polysemy is an indispensable resource of language economy. It would be altogether impracticable to have separate terms for every referent". No wonder polysemy is such a topic of interest in the study and description of natural languages, and poses special problems both in semantic theory and semantic applications, such as lexicography or translation. Nevertheless, except as a source of humour and puns, polysemy is rarely a problem for communication among people. In fact, language users select the appropriate senses of polysemous words "effortlessly and unconsciously [2]."

Sweetser (1990) reviews some of the semantic extensions of perception verbs in English. Her main aim is to provide a motivated interpretation for the relationship between senses of a single word and between diachronically earlier and later senses of a word[3]. Schank and Abelson (1977) have proposed the idea of scripts, widely known sequences of action, such as going to a restaurant[4]. Many scholars, in the past, have conducted studies in the area of language leaning strategies focusing on specific aspects of vocabulary acquisition in relation to particular groups of learners, such as contextual guessing, association, note-taking, dictionary use, and rote repetition. In contrast to their work, this paper attempts to further investigate the cognitive way of polysemy study and explore the lexical meaning extension mechanism by means of metaphor and metonymy, so that students can well master the semantic field and achieve the purpose of polysemous words acquisition through cognitive training.

\section{Lexical Sense Expansion and Evolution}

Language is the most important tool for people to communicate, which dynamically reflects the social development and progress in all areas. Inevitably, new concepts, things, ideas, etc. constantly appear, and accordingly the language changes all the time. Due to the principle of language economy and clarity, humans are always trying to seek a balance between adding new meanings to the existing words and creating new words. Consequently, the combined effects of the above two ways lead to new vocabulary appearance and existing word sense extension. The fact, according to recent studies, is that new vocabulary increases very little, sense shift or transfer prevails. Such a phenomenon leads to the condensation of vocabulary and the reduction of human burden in vocabulary memorization. Thus, the evolution of language mainly leads to the existence of a huge number of polysemous words.

In recent years, with the development of cognitive semantics, many scholars begin to study a variety of linguistic phenomena from a cognitive perspective. They find that a word may have both a 'literal' meaning and one or more

\footnotetext{
* This research is supported by the Social Science Research Common Program of Beijing Municipal Commission of Education (No. 18190114/004) and the Beijing College Students' Scientific Research Program (No. 08150113164).
} 
'transferred' meanings. Polysemes are etymologically and therefore semantically related, and typically originate from metaphoric/metonymic usage (e.g. bank as a building and a financial institution). The distinction is, however, not always straightforward, for words that are etymologically related can, over time, drift so far apart that the original semantic relationship is no longer recognizable, such as pupil (in a school) and pupil (of the eye)[1]..

Cognitive linguists argue that language is both embodied and situated in a specific environment. This can be considered a moderate offshoot of the Sapir-Whorf hypothesis, in that language and cognition mutually influence one another, and are both embedded in the experiences and environments of its users. Human language not only reflects the objective world, but mainly reflects human conception and thinking. They argue that knowledge of linguistic phenomena - i.e., phonemes, morphemes, and syntax - are essentially conceptual in nature. However, they assert that the storage and retrieval of linguistic data are not significantly different from the storage and retrieval of other knowledge, and that use of language in understanding employs similar cognitive abilities to those used in other non-linguistic tasks.

To better understand the meaning of polysemy, there is need to take a close look at the term "polysemy", which is derived from the Greek poly- meaning 'many' and semmeaning 'sense' or 'meaning'. A polyseme is a word or phrase with different, but related senses. As to the division and relatedness of the senses of a lexical term, we often hear different voices. According to no-polysemy or monosemy theory, the senses of polysemous words are represented as very abstract underspecified entities which acquire their specific senses in context. But such a theory has been strongly criticized by cognitive semanticists for the reason that abstract sense is so abstract that it cannot be specified semantically. Both agree that, since polysemy is a vague concept of relatedness, judgments of polysemy can be difficult to make. As applying pre-existing words to new situations is a natural process of language change, the meaning addition is naturally highly motivated and rational, with the least arbitrariness. It is assumed that dominant processes of meaning extension are not only based on conceptual metaphor and metonymy but also employ functional/visual analogy and profiling. Conceptual metaphor and metonymy play the key role in meaning extension.

In Women, Fire, and Dangerous Things, Lakoff draws on the implications of the connectionist system to propose that knowledge is organized not only by metaphoric and metonymic "mappings" but also by "propositional frames" and "image-schematic structure." The combination of these four "structuring principles," which he calls idealized cognitive models or ICMs, compose mini-gestalts that produce myriad categorical linguistic effects. Metonymy and metaphor, as powerful tools of cognition, are not primarily linguistic ornaments but also basic cognitive processes that are pervasive in both thought and perception. They offer mental access to the interpretation of the sense relationships in a lexical field along with image schema, which is frequently used in comprehending spatial prepositions. As prepositions are nonnotional words, the use of schema is beyond the scope of this article.

For example, the word "pen" as a noun means:

a. instrument of writing

b. calligraphy, writing

c. style of writing

d. profession of writing, writer etc.

We know the initial meaning or primary meaning comes from Old French pene, "quill pen; feather". In the old times, people wrote with feathers, and later, writing tools continued to improve. Now, people use a pen to write, the extended senses are all from a figurative use. Gradually its connotation has changed, but the symbolic form of pen has been no change, and the attribute and the material "feather" gradually fade. As we can see, the extended senses are mostly invented based on the metonymic patterns:

MATERIAL FOR FUNCTION (a. instrument of writing);

INSTUMENT FOR ACTION (b. calligraphy, writing);

ACTION FOR RESULT (b. writing, c. style of writing);

INSTRUMENT FOR AGENT OF INSTUMENT (d. profession of writing, writer).

Look at another example: The term "mouse" originally refers to any similar small animal of various rodent and marsupial families. In the sixties, with the development of computer, the word acquired another meaning:

"A palm-sized, button-operated pointing device that can be used to move, select, activate, and change items on a computer screen", this newly added sense is typical of a cognitive metaphoric way. The transferred meaning is based on similarity of the two items in color, shape, size and movement, etc. Besides, the word "mouse" can also refer to "a timid mouse-like person", which might arise from the metaphoric conceptualization of PEOPLE AS ANIMALS. The attributes of a mouse are mapped onto a person.

From the above explanation, we can basically see that the extension of multiple meanings of a lexical item is not arbitrary, but high motivated and justified. Both metaphoric and metonymic grounding is based in our routine experiences. In a sense, the grounding of metonymic concepts is in general more obvious than is the case with metaphoric concepts, since it usually involves direct physical or causal associations.

\section{Understand the Cognitive Mechanism: Metaphor and Metonymy}

It is generally accepted that the senses of polysemous words in cognitive linguistics can be characterized as prototype categorization, and linguistic and encyclopedic knowledge is very hard to keep separate. The incorporation of prototype theory into linguistics becomes a prevailing practice.

Cognitive Semantics believes that the scope of the concept is usually composed of a number of properties. All the senses of a word form a prototype category like a family, linked by certain common attributes among the senses. The characteristics of the family members are the result of the 
interaction of the entity and human cognition. The associated meanings are based on two important human cognitive models: metaphor and metonymy.

Traditionally, metonymy is a figure of speech in discourse used for rhetorical effect. It is a stylistic language operation that makes use of the name of one thing for that of something else, having the function of reference. For instance, in "there were a lot of new faces at the party," the word faces is the name used to refer to people in the context. This is the bestknown metonym of part-for-whole: synecdoche. With the advent of cognitive linguistics, completely different assumptions were made about the nature of metonymies as well as metaphors[5][6][7].

Carita Paradis(2004) claims that metonymy and metaphor are not primarily linguistic figure of speech but basic cognitive processes that are pervasive in both thought and language. Metaphorical and metonymical expressions in language have cognitive function in being used in reasoning, and they are suggestive of how we as human beings think of entities and events within conceptual structures[8].

As to the differences of metaphor and metonymy, scholars attempt to distinguish them in different ways. The prevailing notion is metaphor takes place in two distinctive domains, while metonymy depends on internal-domain mapping. Apart from the term "domain", notions of similarity and continguity are much talked in the present study, though, with a lot of controversies and debates. As domain, similarity and continguity are all based on someone's subjective judgment, it is almost impossible to draw a clear line between them. Whatever the differentiating criteria are, it seems that all agree that both metaphor and metonymy are involved in creating polysemy.

I personally take the differentiation as this. Metaphor and metonymy are similar in various aspects but the major difference is that a metaphor mainly substitutes a concept with another, focusing on attribute-description, whereas a metonymy selects a related term mainly for reference. Both metaphor and metonymy are used to express ideas which are greatly different from the original meaning in the psychic realm. When a person uses a metonymy, the features are not transferred from the original word to the target. But in metaphor, when there is a similarity comparison, the comparison is based on the features or attributes. Cognitively, both metaphor and metonymy are meaning-making in the process. In some cases, both are involved in the understanding of lexical items, such as "head", "brain".

As is demonstrated, metaphor is an extension to a word's meaning on the account of similarity, and metonymy is a way of extending the meaning of a word based on its salience and continguity to another. For example, the association of "chicken (a domestic fowl)" to a person means he is like a coward without confidence, a typical metaphoric mapping of features of a chicken onto a person. It occurs on the basis of conceptual metaphor: PEOPLE ARE ANIMALS. If chicken means the meat or flesh, then it is metonymic use, conforming to the metonymic pattern: MATERIAL FOR FOOD.
As I discuss above, in some phrases or expressions, it can be a blending of both, depending on the contextual discourse. As Rūta Sirvydè(2007) explains the phrase "close-lipped":

Literally, it means "to have one's lips close together". The expression may be regarded both as metonymic and metaphorical within different discourse. If we use this expression in the sense of "to be silent", we have a metonymic relation, because having the lips close together results in silence. However, if we apply the close-lipped expression to describe a talkative person who does not say what we would like to hear from him/her, we have a metaphor, as literally, the lips were not closed in this case. Hence, there is no direct relation between having one's lips close together and telling things not related to the information we want to find out [9].

\section{Cognitive Processing Theory in English Vocabulary Teaching}

In the regular vocabulary teaching, faced with multiple meanings of a word, English teachers often encounter the same problem as the students do. As cognitive linguistics is a new interdisciplinary subject, some English teachers themselves haven't been trained in this area, and they simply teach the students to memorize the word meaning by use of pronunciation and word-formation knowledge, totally ignoring the overall semantic network, while others prefer to explain the individual meaning of a word with Chinese equivalents in a certain unit, ignoring the association between the meanings. Whether in intentional learning or incidental learning, rote memorization is viewed as a low effective way. Without the image association, in-depth vocabulary acquisition becomes impossible, and the memory never lasts over a couple of days. As a result, learning vocabulary, esp. polysemous words remains time-consuming and inefficient. Oxford(1990) mentions consolidate the connection between word form and meaning in memory. Oxford divides these strategies into four general categories: (1) creating mental linkages, (2) applying images and sounds, (3) reviewing well, and (4) employing actions. [10]

For example, the word "hold" has dozens of meanings. How to let the students remember all the meanings and find the associations among them and create necessary mental linkages? Cognitive interpretation of the senses-group serves as a shortcut to long-term memory. For some of the active and powerful words, the slightly different senses can be as many as dozens. If students still use the traditional way to memorize new words such as "Write down every new word you encounter in a notebook; guess what it means in the context in which you hear it or read it ; use any new words you have learned as soon as you learn them", the inefficiency is imaginable. In my class, I would tell my students that the primary and literal meaning of "hold" is "keep, retain, maintain", the other meanings are all derived from this core meaning. As to whether the context is abstract or concrete, it makes no difference. Since, in conceptual metaphor, there are metaphoric patterns like: ABSTRACT AS CONCRETE; PHYSICAL AS MENTAL; VISIBLE AS INVISIBLE, etc. Through these cognitive models and frames, students can well 
see the distinct yet related lexical concepts and their connection. By the use of such an approach, students can easily understand and remember all the meanings in the following expressions:

- I want you to stand beside me and hold the torch.

- He has been trying hard to hold his temper.

- The classroom can hold sixty students.

- We held a party to celebrate our success.

- We hold that all nations should be equal.

- The weather holds fine.

- They held me so that I could not move.

- His speech held them silent.

...

From the above sentences, we can decipher the association of the separate meanings. Anything, either tangible or intangible, can be held with our fingers, our arms and our mind, just as the room holds people, or certain thing is held in a condition. By linking the separate meanings, we see that they are closely related to each other and constitute a comprehensive lexical network. In the interpretation, one of the difficulties is to identify the core meaning of a word, which is either the literal meaning or the primary meaning. One thing is for sure, the meanings have not been attached randomly. Human conceptual systems are embodied and underlie the cognitive meaning-creating models, which are indispensable in language creation and usage.

There is need to point out, traditionally analogy is also regarded as one of the cognitive means. As analogy is based on similar things, too, hereby it is considered as the metaphor. To understand better, let's take a look at the word "hand", its meaning is characterized by a strong functional component which is part of the first literal meaning of the word and highly recurrent in its sense extensions. As we note, the extended meanings are obtained via metaphor and metonymy. For instance, the meanings of "hand" include:

1) the terminal, prehensile part of the upper limb in humans and other primates, consisting of the wrist, metacarpal area, fingers, and thumb. (literal meaning)

2) the corresponding part of the forelimb in any of the higher vertebrates. (metaphor)

3) a terminal prehensile part, as the chela of a crustacean, or, in falconry, the foot of a falcon. (metaphor)

4) something resembling a hand in shape or function, as various types of pointers. (metaphor)

5) a person employed in manual labor or for general duties; worker; laborer. (metonymy: PART FOR WHOLE)

6) a person who performs or is capable of performing a specific work, skill, or action. (metonymy: PART FOR WHOLE)

7) skill; workmanship; characteristic touch (metonymy: INSTUMENT FOR SKILLED ACTION)

8) a person, with reference to ability or skill. (metonymy: PART FOR WHOLE)

9) possession or power; control, custody, or care (metonymy: INSTUMENT FOR FUNCTION)

10) a position, especially one of control, used for bargaining, negotiating, etc. (metonymy: INSTUMENT FOR RESULT)

11) means, agency; instrumentality. (metonymy: INSTUMENT FOR FUNCTION)

12) assistance; aid; active participation or cooperation. (metonymy: INSTUMENT FOR RESULT)

13) style of handwriting; penmanship. (metonymy: INSTUMENT FOR RESULT)

14) a person's signature. (metonymy: INSTUMENT FOR RESULT)

15) a round or outburst of applause for a performer. (metonymy: INSTUMENT FOR RESULT)

16) a linear measure equal to 4 inches. (metaphor)

From the extension of the meanings, we can clearly see that it is metonymization and metaphorization that evoke the meanings. If all the meanings form a category, with no doubt, the literal meaning lies in the central core. What needs to be pointed out is that the first meaning in a dictionary might not necessarily be the literal meaning etymologically.

\section{Conclusions}

To summarize, the idea we are advocating in this paper is the following. Polysemy can be viewed as a lexical field composed of the multiple meanings, which are semantically and historically related. The meaning extension of a lexical unit is not only a semantic phenomenon but also a cognitive processing. The relatedness of the meaning indicate that the non-literal meanings are not picked up arbitrarily. Language is not only a mirror of world, but also a reflection of the world based on human mode of thought. Through the analysis, we convince that dominant processes of meaning extension are based on conceptual metaphor and metonymy, which are differentiated relying on domain approach and notions of similarity and continuity. Conceptual metaphor and metonymy can be introduced into polysemy teaching, and such a practice will greatly improve the efficiency of polysemy acquisition.

\section{References}

[1] Éva Kovács, "Polysemy in Traditional vs. Cognitive Linguistics," Journal of English Studies XI, pp. 3-19, 2011.

[2] Ullmann, Stephen, Semantics: An Introduction to the Science of Meaning, PP. 118, 1959. Oxford: Blackwell.

[3] Sweetser, Eve, From Etymology to Pragmatics. Metaphorical and Cultural Aspects of Semantic Structure, 1990. Cambridge: Cambridge UP.

[4] Schank, Roger C./Robert P. Abelson, Scripts, Plans, Goals and Understanding: An Inquiry into Human Knowledge Structures, 1977. Hillsdale, NJ.

[5] Gibbs, R., The poetics of mind: Figurative Thought, Language and Understanding. Cambridge, 1994. England: Cambridge University Press.

[6] Lakoff, G., Women, Friend, Dangerous Things, 1987. Chicago: University of Chicago Press.

[7] Lakoff, G., \& Johnson, Metaphors We Live by, 1980. Chicago: University of Chicago Press.

[8] Carita Paradis, "Where Does Metonymy Stop? Senses, Facets, and Active Zones", Metaphor and Symbol, 79(4), PP. 245-264, 2004.

[9] Rūta Sirvydè. "Metonymy - a Sister or a Stepdaughter? a Case Study of the Colour of Anger," Respeuctus Philologicus, 2007.

[10] Oxford, R. (1990). Language learning strategies: What every teacher should know, pp. 387. 1990. New York: Newbury House. 